\title{
Research Hotspots and Trends of E-Commerce Credit Evaluation in China Based on CiteSpace
}

\author{
Zhizhen $\mathrm{Bu}^{1 *}$, Jianlin Zhang ${ }^{1}$, Meiyu Wang ${ }^{1}$, Xu Zhang ${ }^{1}$ \\ ${ }^{1}$ Alibaba Business School, Hangzhou Normal University, Hangzhou, Zhejiang 311121, China \\ *Corresponding author. Email: buzhizhenhz@163.com
}

\begin{abstract}
【Significance】 With the rapid development of e-commerce in the era of big data, its credit evaluation becomes more and more important. This paper combs and studies the existing research literature in the field of e-commerce credit evaluation, so as to achieve a comprehensive understanding of the follow-up research hotspots and trends in this field and provide ideas for the development of follow-up research.【Process】 (1) Using the Database of CNKI as the sample source, CiteSpace visual analysis software was used to draw the collaborative network map of high-yield authors, cooperative network map of important institutions, cooccurrence network map of high-frequency keywords and the timezone map of recent five years of research. (2) In order to better understand this field, literature analysis method was used to conduct deep learning research on the papers with high citation and high quality in the sample data. 【Conclusion】 At the present stage, the research in this field is in the bottleneck period. The research hotspots are mainly divided into three aspects: research on $\mathrm{C} 2 \mathrm{C}$ e-commerce platform, research on evaluation system, and research on model establishment. The frontier trends mainly include the research under the background of big data, the system improvement of e-commerce Law, and the application of machine learning algorithm.
\end{abstract}

Keywords: E-commerce, CiteSpace, Credit evaluation system, Credit evaluation model, big data

\section{INTRODUCTION}

China Internet Network Information Center (CNNIC) pointed out in its 45th statistical Report on The Development of Internet in China that by March 2020, the number of netizens in China was 904 million, with an Internet penetration rate of $64.5 \%^{\left[{ }^{1}\right]}$. With the improvement of the Internet penetration rate, China's ecommerce has accelerated its development, and the sinking market, cross-border e-commerce and mode innovation have provided new growth momentum for the online shopping market. According to the data released by the National Bureau of Statistics, in 2019, the national online retail sales volume reached 1,0632.4 billion yuan, an increase of $16.5 \%$ over the previous year.

In the context of massive transaction information, ecommerce, as a commercial activity, is characterized by remoteness, complexity and operability, and its credit problems are much more complex and important than those of traditional enterprises. The problem of ecommerce credit evaluation has become the main bottleneck restricting the development of e-commerce. In order to research on existing e-commerce credit evaluation to do a system comprehensive combing, this paper is based on CNKI database, to retrieve the related literature on the subject of electronic commerce credit evaluation, using CiteSpace to scientific knowledge mapping measurement and visualization analysis and study of literature.

\section{Data SOURCES AND RESEARCH METHODS}

\subsection{Sample sources and data selection}

Based on CNKI literature database as a source of data retrieval, select advanced search, and retrieve specific ways as follows: subject $=\{$ " electronic commerce "or" electricity "and" credit evaluation "\}, as of May 2020, retrieval time due to less research literature in this field, in order to ensure the comprehensiveness of the present study, the source category is set to all journals. After searching, a total of 631 results were obtained, the data were cleaned, and 35 indirect correlation articles such as soliciting articles, catalogues and news were eliminated, a total of 596 valid articles were obtained, which basically covered the research achievements in the field of ecommerce credit evaluation over the years in China. Download and save the document information in Refworks format. The title contains fields such as title, abstract, author, organization, published journal and publication date.

\subsection{Research tools and methods}

This paper adopts the method of metrology ${ }^{[2]}$ and scientific knowledge mapping. At present, CiteSpace independently developed by Drexel University in the United States, 
RefViz tool launched by Thomson and Ominiviz, and VOSviewer developed by CWTS Research Institute of Leiden University in the Netherlands are widely used visual analysis software ${ }^{[3]}$. CiteSpace is a visualization software that is used to analyze the knowledge base, research progress and cutting-edge hotspots in the scientific literature of a certain field. CiteSpace is also translated as "citation space". In the era of big data, it provides possibilities for us to use existing data for applied research of knowledge ${ }^{[4]}$.

In this paper, CiteSpace was used to study 596 sample literatures and draw knowledge maps such as cooperation network, keywords co-existing map and research hotspot time zone map of core authors and major research institutions in the field of e-commerce credit evaluation in China. Combined with the core literature, the research status, hotspot, frontier and development trend of this field are analyzed by the method of literature research. In order to more comprehensively and vividly explore the current e-commerce credit evaluation field, for the follow-up research work to prepare.

\section{RESEARCH TREND ANALYSIS}

\subsection{Development trend analysis}

From 2001 to 2020, the annual publication volume of 596 core literatures on e-commerce credit evaluation included in CNKI is shown in Figure 1. It can be seen from the distribution trend of the annual publication volume that scholars' attention to this field has gradually increased from slow to rapid growth and then gradually leveled off. Its overall research process is basically consistent with the development of e-commerce and there is a certain lag time.

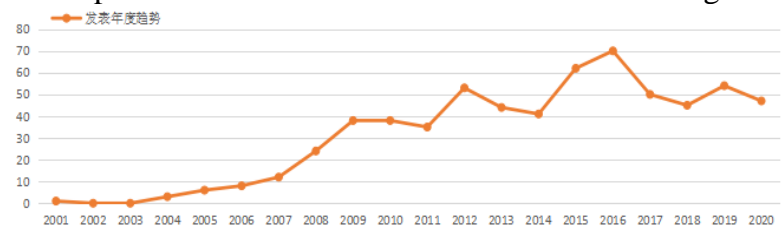

Figure 1 Trend chart of the number of published papers over the years in the field of e-commerce credit evaluation

Shao B.J. et al. (2006) $)^{[5]}$ proposed that the national authorities could carry out third-party identity authentication and credit authentication to improve the existing system. Chen D. et al. (2006) ${ }^{[6]}$ put forward that the key point of constructing the credit management system of e-commerce in China should be the interenterprise credit management. Piao C.H. et al. (2007) ${ }^{[7]}$ improved the existing $\mathrm{C} 2 \mathrm{C}$ credit evaluation model and established a new credit evaluation model, proposed a new algorithm, calculated the weighted average credit score and credit degree of the evaluated user by weighing and considering the credit degree, transaction times and transaction amount of the trading party, and then determined the credit rating of the evaluated user. Liu Z.F. et al. (2016) ${ }^{[8]}$ used fuzzy AHP to assign weights to each index, built a credit evaluation model matching with big data, and combined advanced machine learning tools for training and prediction, thus building a complete and dynamic credit evaluation system for cross-border e-commerce. Xu Q.F. et al. $(2017)^{[9]}$ proposed that a multi-factor correction model of seller's credit score should be established to explain the concept of cumulative loss of store consumption, and the effectiveness of the model was verified by using the neural network quantile regression model and corresponding evaluation indicators.

\subsection{Core author analysis}

A statistical analysis of the authors of e-commerce credit evaluation research can identify the core authors and major contributors in this field. The authors were analyzed using CiteSpace to obtain a map of the study authors' collaboration, as shown in Figure 2, and the high-yielding authors shown in Table 1. It can be seen that the representative authors of this research field are $\mathrm{Wu} \mathrm{P}$., Zhou L.G., etc.

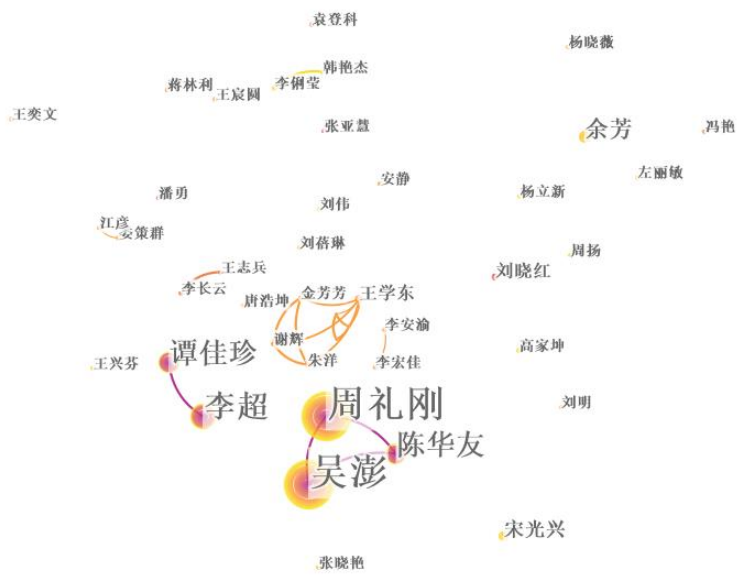

Figure 2 Collaborative network of prolific authors on e-commerce Credit Evaluation

Core author refers to the a representative in the research field, the author of the contribution to the larger, and the determination of core authors can draw lessons from price rule: in the same topic, half of the papers written by a group of prolific authors, the author set about equal to the square root of the total number of all the authors, the number of which the minimum number of core authors and the most prolific authors identificated and between the following relations:

$$
M p=0.749 \sqrt{N_{P} \max }
$$


Table 1 High-yield author of literature on ecommerce credit evaluation

\begin{tabular}{|c|c|c|c|}
\hline SN & Author & Number & Year \\
\hline 1 & Wu Peng & 20 & 2001 \\
\hline 2 & Zhou Ligang & 20 & 2004 \\
\hline 3 & Li Chao & 10 & 2001 \\
\hline 4 & Tan Jiazhen & 8 & 2001 \\
\hline 4 & Chen Huayou & 8 & 2003 \\
\hline 5 & Yu Fang & 5 & 2016 \\
\hline 6 & Zuo Limin & 4 & 2015 \\
\hline 6 & Song Guangxing & 4 & 2009 \\
\hline
\end{tabular}

Of core authors in the field of electronic commerce credit evaluation on statistical analysis of the most prolific authors $\mathrm{Wu}$ P. post number is 20 , according to take up the whole principle, which published more than 4 articles and the authors of the paper as the core authors, a total of eight people, the number of published literature a total of 79 articles, $13.3 \%$ of all publications, is far less than $50 \%$, do not tally with the price law, therefore, our country electronic commerce credit evaluation of the research has not yet formed a proper core authors.

It can be seen from Figure 2 that the nodes are relatively dispersed and have few connections with each other. The prolific authors in this field are Wu P. and Zhou L.G., followed by Li C., Tan J.Z. and Chen H.Y., whose research on e-commerce credit evaluation accounts for well over $50 \%$ of the total number of articles by core authors. It can be seen that the author group fault in this field is relatively obvious, and most scholars are still in the research and exploration stage.

\subsection{Major mechanism analysis}

According to the analysis of institutions by CiteSpace, the map of major research institutions is shown in Figure 3. The institutions with the most publications are China Manufacturing Development Institute of Nanjing University of Information Technology and Nanjing University (20 papers). The top 10 institutions with the most publications are shown in Table 2. As can be seen from the co-occurrence map of institutions, the relationship between institutions is too diffuse, and only a few institutions have cooperative relationships at present. Further research should focus more on strengthening inter-agency cooperation.
Nanjing information engineering university of China's manufacturing industry development research institute and Anhui university school of mathematical science cooperation published language based on the consensus model of e-commerce credit risk evaluation methods from the perspective of linguistic assessment information $^{[10]}$, using the method of multiple attribute group decision making, individual and group consensus measure language is put forward, and focused on the decision of the low level of synchronic group integer programming model was constructed to adjust the decision-makers of the original language information, finally put forward a model based on language understanding of e-commerce credit risk evaluation method.

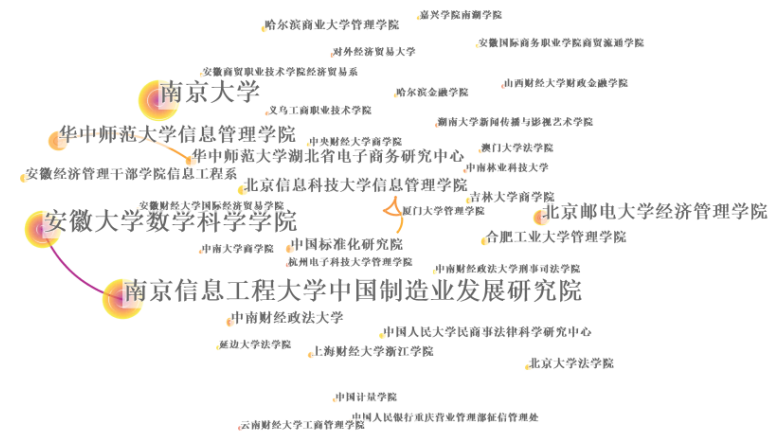

Figure 3 Cooperative network map of important institutions in e-commerce Credit Evaluation research

Table 2 E-commerce credit evaluation of the main research institutions

\begin{tabular}{|c|c|c|c|}
\hline SN & Institution & Number & Year \\
\hline 1 & $\begin{array}{c}\text { China Manufacturing Development } \\
\text { Research Institute, Nanjing } \\
\text { University of Information } \\
\text { Technology }\end{array}$ & 20 & 2001 \\
\hline 1 & Nanjing university & 20 & 2001 \\
\hline 3 & $\begin{array}{c}\text { School of Mathematics and } \\
\text { Science, Anhui University }\end{array}$ & 18 & 2001 \\
\hline 4 & $\begin{array}{c}\text { School of Information } \\
\text { Management, Central China } \\
\text { Normal University }\end{array}$ & 9 & 2013 \\
\hline 6 & $\begin{array}{c}\text { School of Economics and } \\
\text { Management, Beijing University of } \\
\text { Posts and Telecommunications }\end{array}$ & 8 & 2009 \\
\hline 7 & $\begin{array}{c}\text { Hubei Electronic Commerce } \\
\text { Research Center of Central China } \\
\text { Normal University }\end{array}$ & 5 & 2013 \\
\hline $\begin{array}{c}\text { School of Information } \\
\text { Management, Beijing University of } \\
\text { Information Technology }\end{array}$ & 5 & 2016 \\
\hline
\end{tabular}




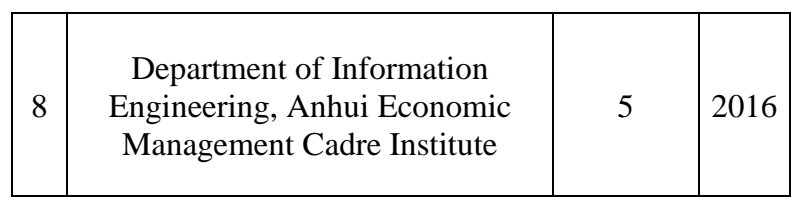

At present, the research on e-commerce credit evaluation is still in the stage of incomplete but rapid development. More and more scholars and institutions are involved in it, constantly improving the quantity and quality of the academic research. While developing continuously, scholars and research institutions should also pay attention to the research hotspots and trends of e-commerce credit evaluation.

\section{RESEARCH FOCUS AND TREND ANALYSIS}

\subsection{Research focus analysis}

In this paper, the research focus of e-commerce credit evaluation is mainly studied through the visual analysis of keywords in the samples. By operating CiteSpace, the keywords in the sample literature are analyzed. After fine-tuning the production network map, the keywords map shown in Figure 4 is obtained. The nodes in the knowledge map represent the frequency of the keyword, and the size of the nodes is proportional to the frequency. The thickness of the lines between keywords represents the degree of association between the two, and the degree of association is proportional to the co-occurrence frequency. It is obvious that the highfrequency keywords are "C2C", "credit evaluation system", "big data" and "credit evaluation model", etc., indicating that the current research on cross-border ecommerce concerned by Chinese scholars mainly focuses on these fields. Keywords such as "analytic hierarchy process", "business management" and "credit rating" also appear in the knowledge map, but with small nodes, they belong to the topic of less research and lack of in-depth exploration, which are likely to represent the research trend in the future.

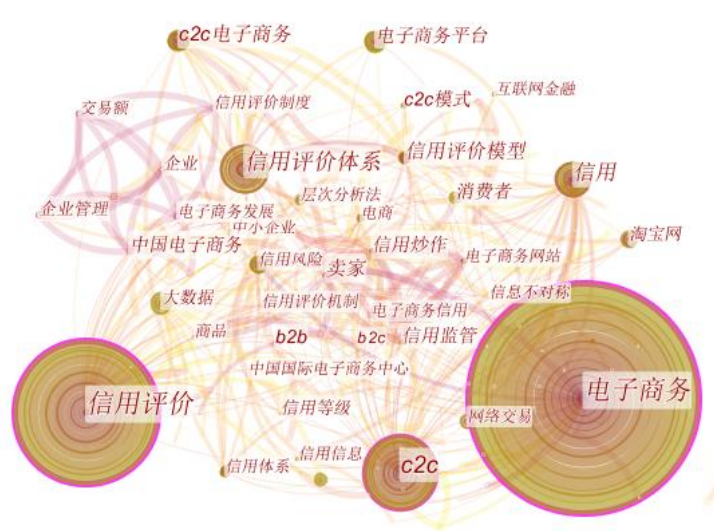

Figure 4 Research on credit evaluation of e-commerce High-frequency keywords co-occurrence spectrum

These high-frequency keywords shown in Figure 4 represent the research hotspots in the field of ecommerce credit evaluation in recent years and the correlation degree among them. Among them, "ecommerce" and "credit evaluation" have the highest frequency and the largest node, covering the whole time of the study. However, since "e-commerce" and "credit evaluation" are used as the retrieval keywords in this paper, these two keywords need to be eliminated here. Table 3 shows the keywords of high-frequency and high-centrality in the research field. It can be concluded that the research hotspots of e-commerce credit evaluation mainly focus on the credit evaluation of $\mathrm{C} 2 \mathrm{C}$ e-commerce platform, how to establish the credit evaluation system and model, and the research of ecommerce credit evaluation taking Taobao as an example.

Table 3 Keywords of high-frequency and highcentrality in e-commerce credit evaluation research field

\begin{tabular}{|c|c|c|c|}
\hline Hotspots & Number & Centrality & Year \\
\hline C2C & 72 & 0.31 & 2006 \\
\hline Credit evaluation system & 51 & 0.19 & 2006 \\
\hline Credit & 41 & 0.15 & 2005 \\
\hline The credit risk & 29 & 0.02 & 2001 \\
\hline C2C e-commerce & 28 & 0.08 & 2008 \\
\hline E-commerce platform & 28 & 0.07 & 2001 \\
\hline Big data & 22 & 0.06 & 2015 \\
\hline Taobao & 19 & 0.08 & 2009 \\
\hline Credit evaluation model & 18 & 0.07 & 2007 \\
\hline Credit system & 16 & 0.05 & 2009 \\
\hline Consumers & 13 & 0.07 & 2007 \\
\hline Credit hype & 12 & 0.07 & 2006 \\
\hline
\end{tabular}


Through the analysis of co-existing knowledge map, the above research hotspots of e-commerce credit evaluation are analyzed in a quantitative and visual way, which shows the research hotspots in this field. By integrating the key word map and the content analysis of existing research literature, the research hotspots of E-commerce credit evaluation in China are classified into the following aspects:

(1) Research on credit evaluation of $\mathrm{C} 2 \mathrm{C}$ e-commerce platform. In terms of e-commerce platform credit evaluation, it can be subdivided into B2C e-commerce platform and $\mathrm{C} 2 \mathrm{C}$ e-commerce seller credit evaluation. Because $\mathrm{C} 2 \mathrm{C}$ mode characteristic of the participation subject widely, transaction anonymity and asymmetry of time and space and so on risk, such as fake and shoddy, malicious slander, and lack of credit fraud credit behavior greatly hindered the development of $\mathrm{C} 2 \mathrm{C}$ electronic business platform ${ }^{[11][12]}$, about how to establish a scientific and feasible c2c credit evaluation model in order to solve the $\mathrm{C} 2 \mathrm{C}$ credit crisis to be the concern of the scholars. Li R.X. et al. ${ }^{[13]}$ proposed to use the interval distribution of commodity prices to score points for successful transactions, and to use the deduction coefficient of credit ratings to deduct points for failed transactions of different credit ratings in order to solve the problem of credit hype and periodic deception. Yang Y. ${ }^{[14]}$ pointed out that $\mathrm{C} 2 \mathrm{C}$ platform merchants have a trend of professionalism, and the traditional credit evaluation system based on individuals is no longer applicable. The establishment of a dynamic evaluation model of credit value over time has a positive effect on the construction of network trading environment. Liang $\mathrm{W}$. et al. ${ }^{[15]}$ proposed to establish a new evaluation system based on transaction amount, seller credit and buyer credit and introduced a weighted average based credit evaluation algorithm to form a dynamic $\mathrm{C} 2 \mathrm{C}$ credit evaluation model.

(2) Research on e-commerce credit evaluation system. Credit evaluation system refers to the general term of the evaluation elements, evaluation indexes, evaluation methods, evaluation criteria, evaluation weights and evaluation grades used in the objective and fair evaluation of the credit status of the evaluated objects. How to establish a complete set of e-commerce credit evaluation system is the key to the effectiveness of the evaluation. Aiming at the problems existing in seller's credit evaluation system in $\mathrm{C} 2 \mathrm{C}$ e-commerce, Su S.Y. et al. ${ }^{[16]}$ designed a new seller's credit evaluation system, and used the fuzzy complementary judgment matrix ranking method to determine the weight of each factor, so as to give the calculation process of seller's credit score and improve new ideas for credit management. $\mathrm{Li}$ J.M. et al. ${ }^{[1]]}$ believe that for the credit evaluation indicators of small and medium-sized enterprises engaged in e-commerce, the four main indicators, namely business ability, profitability, debt paying ability and development ability, as well as three indicators of expansibility, network marketing ability, network customer service ability and network management ability, are the most important. On the basis of a large-scale questionnaire survey, Yang J.Z. et al. ${ }^{1} 18$ ] applied principal component analysis to summarize five indicators that have an important impact on the development of cross-border e-commerce, one of which is electronic customs clearance index, which is subdivided into three specific indicators of electronic customs clearance, cargo inspection and tax collection. Zhang Y.Q. et al. ${ }^{[19]}$ chose third-party data, e-commerce platform transaction data and network trajectory data as three dimensions to build a big data credit collection system in the research on the development of business credit system construction of the Information network.

(3) Establishment and research of e-commerce credit evaluation model. For credit evaluation, BP artificial neural network model and random forest model are considered to be the best machine learning methods for classification. Tian B. et al. ${ }^{[20]}$ introduced the perceptive trust and reputation system into the model and judged the credit status of both parties by comparing them. Jia Y.T. et al. ${ }^{[21]}$ proposed a c2C credible credit evaluation model. Based on the historical transaction records, the dynamic calculation method was adopted on the basis of comprehensive consideration of the transaction amount, credit of the buyer and the seller, transaction times, negative evaluation times and unevaluated transactions, so as to provide reliable basis for the success of the transaction. Zhang R.Y. et al. ${ }^{[2]}$ used SPSS two-step clustering method and MATLAB BP neural network toolbox to build a three-layer BP neural network, and established a $\mathrm{C} 2 \mathrm{C}$ credit evaluation model through training and simulation experiments. According to the advantages and disadvantages of data mining, Liu J.J. ${ }^{[23]}$ used naive Bayes algorithm and BP neural network to design c2C e-commerce credit evaluation dynamic model to establish a credit evaluation model with higher accuracy.

\subsection{Research trend analysis}

Through the analysis of high-frequency keywords in recent five years, the hotspots and frontiers of each year are obtained as shown in Table 5, and then the research hotspots and trend changes in recent years are reflected. It can be found that big data, $\mathrm{C} 2 \mathrm{C}$, credit evaluation system and credit risk have been concerned by scholars and become inseparable topics in recent years. After AHP became a high-frequency keyword in 2015, its popularity was not high. It can be seen that most scholars are exploring more appropriate analysis methods in subsequent studies. The problem of information asymmetry was widely mentioned by scholars in 2016, and corresponding countermeasures 
were proposed in the research. The research on the integration of high-frequency keywords Internet finance and e-commerce credit evaluation in 2017 has a positive impact on the single-direction research. In 2018, high-frequency keyword machine learning is also a popular method for scholars to improve the credit evaluation model. E-commerce Law officially came into effect in 2019, which is also a hot key word in this field in 2019, indicating scholars' grasp of the timeliness of the research field.

Table 4 From 2015 to 2019 e-commerce credit evaluation research high-frequency keywords

\begin{tabular}{|l|l|}
\hline Year & \multicolumn{1}{|c|}{ High-frequency keywords } \\
\hline 2015 & $\begin{array}{l}\text { C2C, Big data, Credit evaluation system, AHP, Taobao, C2C } \\
\text { e-commerce, Third-party payment, countermeasures, Credit } \\
\text { system, The credit risk }\end{array}$ \\
\hline 2016 & $\begin{array}{l}\text { Credit, C2C, The credit risk, SMES, Online trading, Big } \\
\text { data, C2C e-commerce, The rule of law, Credit evaluation } \\
\text { system, Information asymmetry }\end{array}$ \\
\hline 2017 & $\begin{array}{l}\text { Big data, C2C, Credit evaluation system, Online finance, Cross- } \\
\text { border e-commerce, The third party, SMES, Taobao, The good } \\
\text { faith system, The regulatory system }\end{array}$ \\
\hline 2018 & $\begin{array}{l}\text { Big data, Credit evaluation, Cross-border e-commerce, Credit } \\
\text { evaluation system, E-commerce platform, Credit system, Brush a } \\
\text { single letter, Credit evaluation model, Credit management , } \\
\text { Machine learning }\end{array}$ \\
\hline & $\begin{array}{l}\text { Consumers, Electronic Commerce Law, Big data, The rule of } \\
\text { law, The indicator system, Brush the single, The credit risk, } \\
\text { C2C e-commerce, Big Data Era, Credit evaluation system }\end{array}$ \\
\hline
\end{tabular}

By using CiteSpace to analyze the keywords published from 2015 to 2020 in 596 sample literatures, the time zone map of keywords can be obtained as shown in Figure 5. In chronological order from left to right, each circle represents a key measure and is fixed in the position of the year in which it first appeared. In 2015, the number of keywords appeared the most, and the number of keywords appeared the most. In the following years, the number of new keywords and the number of new keywords declined precipice, so it can be concluded that the innovation points in this field were successively reduced. In recent years, all of them were the bottleneck period for the development of this field, and most of the research results were based on the further improvement of previous studies. The new Ecommerce Law issued in 2020 is likely to be the frontier trend of the following research. The three-stage transaction proposed in 2019, which divides the transaction process into three stages for credit evaluation and analysis, is also a new highlight of the research. Neural network and Naive Bayes have also become hot spots in 2020. In the future, researches on e-commerce credit evaluation are likely to be more deeply integrated with machine learning algorithms. 


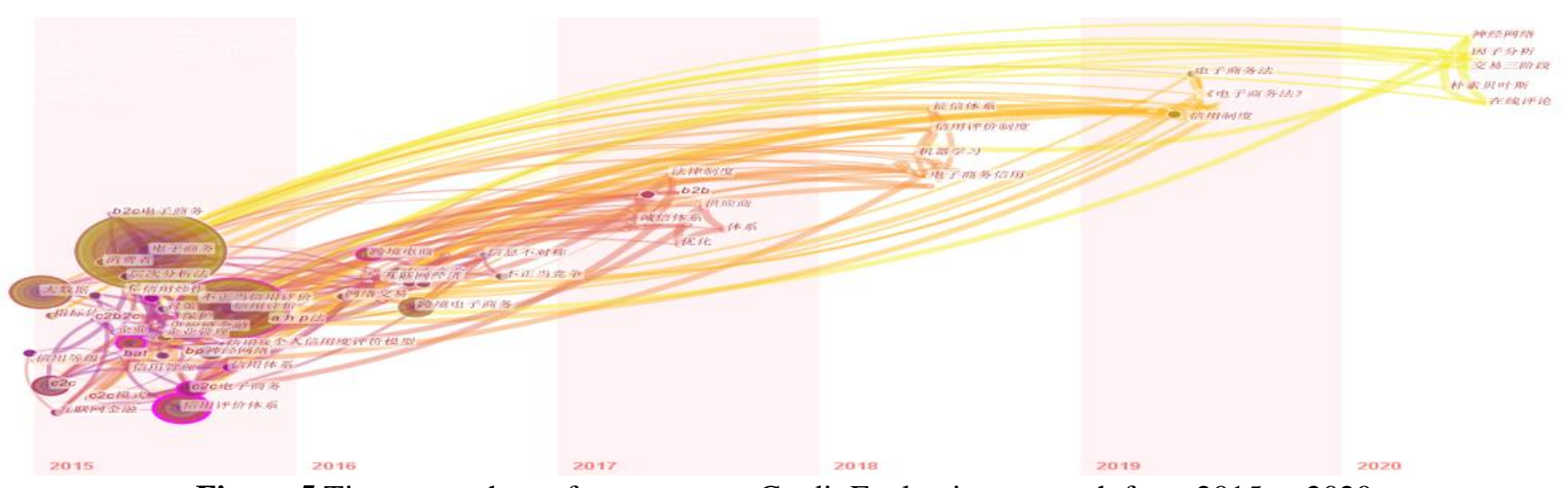

Figure 5 Time zone chart of e-commerce Credit Evaluation research from 2015 to 2020

\section{RESEARCH CONCLUSION AND PROSPECT}

\subsection{Conclusion}

Based on the visual analysis of knowledge map of literature related to e-commerce credit evaluation in CNKI database, as well as the combing and summary of literature, the following conclusions are drawn:

1. The e-commerce credit evaluation field in China is currently in the stable development stage of research. However, it can be found from the trend chart of the number of posts and the time zone chart of research that the number of annual posts in recent years has decreased compared with the rapid development period, and there are few new hot keywords, indicating that the current research is in the bottleneck period and the development is relatively slow. In the future research, scholars should pay attention to find innovation points in the research, so as to make a breakthrough on the basis of the current research.

2. At present, the core authors of e-commerce credit evaluation in China are Wu P. and Zhou L.G., and the core author group has not been formed yet; The main research institutes are: China manufacturing development institute and nanjing university; Research hotspots are mainly divided into three aspects: research on credit evaluation of $\mathrm{C} 2 \mathrm{C}$ e-commerce platform, research on e-commerce credit evaluation system, and research on e-commerce credit evaluation model establishment.

3. At present, the research frontier trends in the field of e-commerce credit evaluation in China mainly include: the research on e-commerce credit evaluation under the background of big data, the improvement of the credit evaluation system based on the E-commerce Law, and the application of machine learning algorithm in the field of e-commerce credit evaluation.

\subsection{Lack of research and prospect}

At present, few papers have used CiteSpace to conduct literature review on researches in the field of ecommerce credit evaluation, but this paper still has the following deficiencies:

1. Due to the small number of core literatures related to e-commerce credit evaluation in the CNKI database, the literature samples selected in this paper are all literatures, including some literatures of low quality, which may contribute to the accuracy of the research results in this paper.

2. Due to the system problems of CiteSpace, it is impossible to conduct journal and co-citation studies on the sample data, which makes the study of this paper not comprehensive enough. In subsequent studies, Web of Science can be selected for a more comprehensive study to analyze the research status and trend of ecommerce credit evaluation.

\section{ACKNOWLEDGEMENT}

Fund Project: Research on the construction of cross border e-commerce laws and regulations -Based on the perspective of international comparison (2014GH007).

\section{REFERENCES}

[1] CNNIC, The 45th Statistical Report on Internet Development[R].

[2] Ding X.D. Fundamentals of Literature Metrology[M]. Beijing University Publishers, 1992:220-232. 
[3] Chen Y., Chen C.M., Liu Z.Y., Hu, Z.G., Wang, $\mathrm{X} . \mathrm{W}$. The methodology function of Cite Space mapping knowledge domains [J]. Studies in Science of Science, 2015, 33(02): 242-253.

[4] Chen C. CiteSpace II: Detecting and visualizing emerging trends and transient patterns in scientific literature[J]. Journal of the American Society for Information Science and Technology, 2006,57(3):359377.

[5] Shao B.J., Li R. Research on Credit Evaluation System of Auction Website[J]. Statistics \& Decision, 2006(04):89-91.

[6] Chen D., Zhao S.K., Gong S.L. Study on Building the Credit Management System of Electronicbusiness[J]. Information Science, 2006(01):47-51.

[7] Piao C.H., An J., Fang M.Q. Research on Credit Evaluation Model and Algorithm for C2C E-commerce Website[J]. Journal of Information, 2007(08):105-107.

[8] Liu Z.f. Analysis on the Construction of Crossborder E-commerce Credit Evaluation System under the Background of Big Data[J]. China Business and Market, 2016,30(06):58-64.

[9] Xu Q.F., Wang T., Jiang C.X., Yang S.L. The Creation and Validity Test of Seller's Credit Scoring Multifactorial Correction Model in E-commerce-A Case Study on Taobao [J]. Soft Science, 2017,31(01):105-108+113.

[10] Wu P., Zhou L.G., Chen H.Y. An approach to Ecommerce credit risk assessment based on linguistic consensus model[J/OL]. Control and Decision, 2020:17.

[11] You T.H., Li L., Yu Z.C. Study of Establishment and Method of Seller Credit Evaluation Index System for C2C E-Commerce [J]. Management and Service Science. 2012, 23(2):78-81.

[12] Tian S.1. Analysis and Research of C2C Ecommerce Credit Evaluation [D]. Xidian University,2008.

[13] Li R.X., Gao C., Gu X.W., Lu Z.D. Research on credit counting and risk evaluation for $\mathrm{C} 2 \mathrm{C}$ ecommerce[J]. Journal on Communications, 2009,30(07):78-85.
[14] Yang Y. A Dynamic Trust Evaluation Model on C2C Marketplaces[J]. Information Science, 2010,28(04):563-566.

[15] Liang W., Zhang Q. Research of Electronic Commerce Credit Model on the Basis of Dynamic Game Analysis[J]. Journal of Shandong University of Science and Technology (Social Sciences), 2017,19(03):74-83.

[ 16] Su S.Y., Yang D.H. The Formulation and Application of Seller Credit Evaluation System for C2C E-commerce[J]. Journal of Intelligence, 2009,28(11):68-72+26.

[17] Li J.M., Wu J.Y., Zhang J.J., Ke L.M. Study on SMEs credit evaluation system in E-commerce environment[J]. Systems Engineering-Theory \& Practice, 2012,32(03):555-560.

[18] Yang J.J., Zheng B.X., Yang L.F. Research on Cross-border E-commerce Index System Based on Factor Analysis[J]. Finance \& Trade Economics, 2014(9):94-102.

[19] Zhang Y.Q., Sun J.F., Wang Y. Construction of "Internet of Credit"Business Credit System[J]. Journal of Central University of Finance \& Economics, 2015(4):90-99.

[20] Tian B., Qin Z. Study on the Trust Model of Ecommerce[J]. Journal of Information, 2007(04):42-44.

[21] Jia Y.T., Yu H.Q. Trustworthy Credit Reputation Model Based on $\mathrm{C} 2 \mathrm{C}[\mathrm{J}]$. Computer Engineering, 2010,36(18):256-258.

[22] Zhang R.Y., Liu J., Zuo M. Establishment of C2C E-commerce Credit Evaluation Model Based on BP Neural Network[J]. China Economic \& Trade Herald, 2015(05):55-58.

[23] Liu J.J. Research on C2C E-commerce Business Credit Evaluation Model[D]. Jilin University, 2018. 